SUBJECT AREAS:

BIOANALYTICAL

CHEMISTRY

ELECTROCATALYSIS

Received

8 May 2014

Accepted

22 July 2014

Published

28 August 2014

Correspondence and requests for materials should be addressed to

M.P. (pumera@ntu. edu.sg)

\section{Direct In Vivo Electrochemical Detection of Haemoglobin in Red Blood Cells}

\author{
Rou Jun Toh ${ }^{1,2}$, Weng Kung Peng ${ }^{2}$, Jongyoon Han ${ }^{2,3}$ \& Martin Pumera'
}

'Division of Chemistry \& Biological Chemistry School of Physical and Mathematical Sciences, Nanyang Technological University, 637371, Singapore, ${ }^{2}$ BioSystems \& Micromechanics IRG (BioSyM), Singapore-MIT Alliance for Research and Technology (SMART) Centre, 1 CREATE Way, \#04-13/14 Enterprise Wing, 138602, Singapore, ${ }^{3}$ Department of Electrical Engineering and Computer Science, Department of Biological Engineering, Massachusetts Institute of Technology, Cambridge, Massachusetts, USA.

The electrochemical behavior of iron ion in haemoglobin provides insight to the chemical activity in the red blood cell which is important in the field of hematology. Herein, the detection of haemoglobin in human red blood cells on glassy carbon electrode (GC) was demonstrated. Red blood cells or raw blood cells was immobilized on a glassy carbon electrode surface with Nafion films employed to sandwich the layer of biological sample firmly on the electrode surface. Cyclic voltammetry (CV) analyses revealed a well-defined reduction peak for haemoglobin at about $-0.30 \mathrm{~V}$ (vs. $\mathrm{Ag} / \mathrm{AgCl}$ ) at the red blood cell (GC-Nf-RBC-3Nf) and blood (GC-Nf-B-3Nf) film modified GCE in a pH 3.5 phosphate buffer solution. We further demonstrated that the complex biological conditions of a human red blood cell displayed no interference with the detection of haemoglobin. Such findings shall have an implication on the possibilities of studying the electrochemical behaviour of haemoglobin directly from human blood, for various scientific and clinical purposes.

$\mathrm{n}$ human blood, the physiological role of haemoglobin $(\mathrm{Hb})$ is the storage and transport of molecular oxygen $\left(\mathrm{O}_{2}\right)$ and carbon dioxide $\left(\mathrm{CO}_{2}\right)$. The metalloprotein has a molecular weight of $64.5 \mathrm{kDa}$ and is the majority substance in red blood cells (RBCs). Haemoglobin contains four polypeptide subunits (two $\alpha$ and two $\beta$ subunits) of similar structure, each of which has an iron-bearing heme within molecularly accessible crevices ${ }^{1,2}$. The iron ion may be in either the II or III oxidation state. In its ferrous state ( $\left.\mathrm{HbFe}^{\mathrm{II}}\right)$, haemoglobin binds oxygen to form oxyhaemoglobin $\left(\mathrm{Oxy}-\mathrm{Hb} ; \mathrm{HbFe}^{\mathrm{II}}-\mathrm{O}_{2}\right)$. However, in its ferric state $\left(\mathrm{HbFe}^{\mathrm{III}}\right)$, methaemoglobin $(\mathrm{Met}-\mathrm{Hb})$ loses oxygen-binding capacity. $\mathrm{Fe}^{\mathrm{II}}$ is oxidized to $\mathrm{Fe}^{\mathrm{III}}$ spontaneously in small amounts in human red blood cells (1-2\% of $\mathrm{Hb}$ ), and if not moderated by internal reduction mechanisms within the red blood cell, high levels of Met-Hb (methemoglobinemia) could result in fatality ${ }^{3-5}$.

Activity measurement of proteins such as haemoglobin may be crucial to investigate the nature of many in vivo energy conversion processes, from photosynthesis to respiration, most of which are facilitated by these protein molecules $^{6-9}$. In particular, the direct electrochemical detection of metalloproteins has been applied to bioanalysis ${ }^{10,11}$. The iron ion in haemoglobin serves as a redox-active center. Hence, the direct electron transfer reactions of haemoglobin may provide fundamental understanding of its redox behaviour within the red blood cell. It is important to monitor accurately such reactions because abnormal shift in chemical activity in the red blood cell usually occurs due to primary hematologic disorders like anemia, or a wider variety of other diseases which produces secondary abnormalities of the blood ${ }^{12,13}$. Moreover, it is essential to determine the concentration of haemoglobin in blood samples as an indication of the red blood cell count in blood and hence, the oxygen transport ability of blood.

In this paper, our goal is to probe into the electrochemical behaviour of the iron ion of haemoglobin contained in RBCs. Previous studies have shown that direct electron transfer to cell-free haemoglobin redox center is possible ${ }^{14-17}$. However, little is studied about the voltammetric responses obtained directly from red blood cells as the electrochemistry of haemoglobin within red blood cells may be complicated due to the presence of the cellular membrane and complex biological environment. Herein, we would like to address the following basic questions: 1) is the electrochemical activity of iron ion in haemoglobin observed with the chemical systems of red blood cells and blood; and 2) is the electrochemical activity of iron ion in haemoglobin interfered by the biological complexity of red blood cells. If so, what is happening at the iron centre of haemoglobin in these systems. The commonly used glassy carbon electrode would serve as the surface for the investigation of such electrochemical behaviour. 

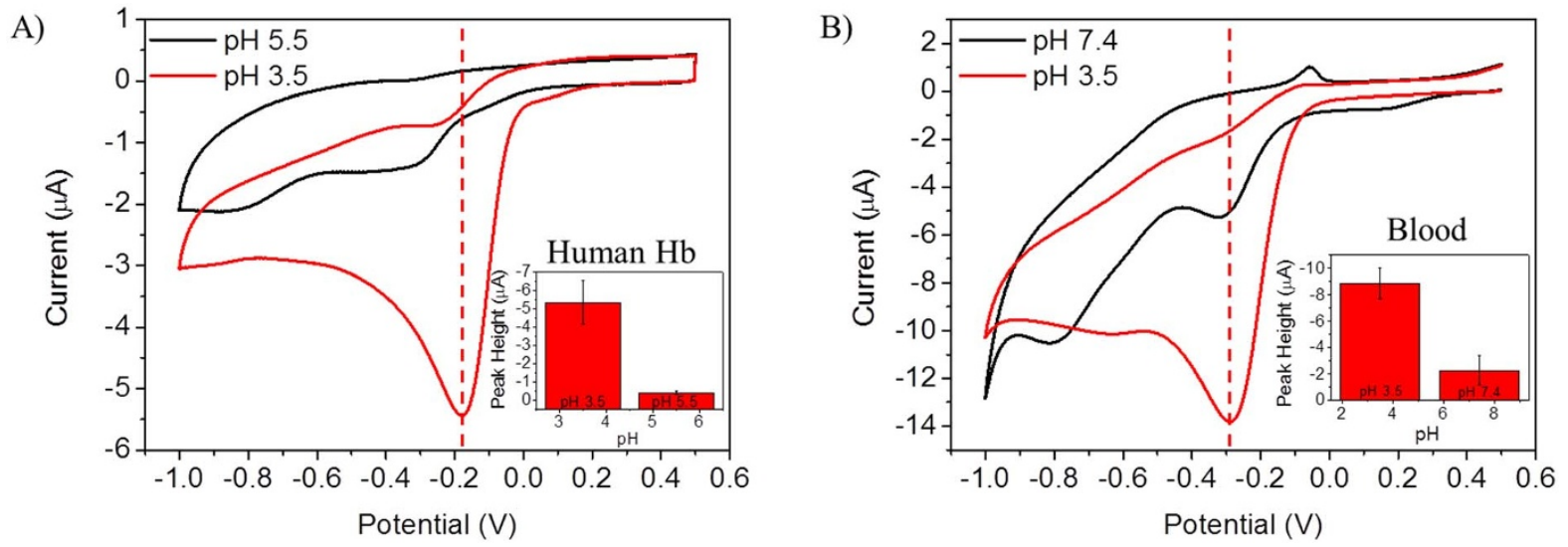

Figure $1 \mid$ (A) Cyclic voltammograms (from $+0.5 \mathrm{~V}$ to $-1.0 \mathrm{~V}$ ) were obtained in aqueous $50 \mathrm{mM}$ phosphate buffer at $\mathrm{pH} 5.5$ and 3.5 for the electrochemical reduction of human haemoglobin $(0.05 \mathrm{mg} / \mathrm{mL}, 0.78 \mu \mathrm{M})$ at GC electrodes. Reduction peak potential of haemoglobin decreases with an increase in $\mathrm{pH}$. Scan rate is $0.1 \mathrm{Vs}^{-1}$. Inset: Reduction peak height of cyclic voltammograms at different $\mathrm{pH}$ values. Error bars represent $\mathrm{RSD}$ ( $n=3$; $95 \%$ confidence interval). (B) Cyclic voltammograms (from $+0.5 \mathrm{~V}$ to $-1.0 \mathrm{~V}$ ) were obtained in aqueous $50 \mathrm{mM}$ phosphate buffer for the electrochemical reduction of blood at $\mathrm{pH} 3.5$ and $\mathrm{pH}$ 7.4. Blood concentration was chosen to be $1 \times 10^{3}$ cells $/ \mu \mathrm{L}$. Reduction peak current magnitudes decreases with an increase in $\mathrm{pH}$. Scan rate is $0.1 \mathrm{Vs}^{-1}$. Inset: Reduction peak height of cyclic voltammograms at different $\mathrm{pH}$ values. Error bars represent $\mathrm{RSD}(n=3$; $95 \%$ confidence level).

\section{Results and Discussion}

Experimental conditions were first optimised by investigating the reduction of haemoglobin in solution at different $\mathrm{pH}$ values on bare GC electrodes using cyclic voltammetry $(\mathrm{CV})$. A marked effect of $\mathrm{pH}$ on the voltammetric response for haemoglobin may be observed in Figure 1A. The reduction of haemoglobin shows a peak at approximately $-0.3 \mathrm{~V}$ and $-0.15 \mathrm{~V}$ at $\mathrm{pH} 5.5$ and $\mathrm{pH} 3.5$ respectively. A decrease in $\mathrm{pH}$ shows a shift in reduction peak potential to less negative values. Accompanying this observation, a decrease from $\mathrm{pH} 5.5$ to $\mathrm{pH} 3.5$ saw an almost eleven-fold increase in the charge under the voltammetric response (Figure 1 inset). The observed $\mathrm{pH}$ dependence of the redox process is in agreement with previously reported works ${ }^{17,18}$, suggesting the involvement of $\mathrm{H}^{+}$. Similarly, a study on $\mathrm{pH}$ dependence was carried out for blood at GC-Nf-B-3Nf electrodes using cyclic voltammetry (Figure 1B). A significant effect of $\mathrm{pH}$ on the voltammetric response for blood was noted. The reduction of blood shows a peak at about $-0.3 \mathrm{~V}$ at both $\mathrm{pH} 3.5$ and $\mathrm{pH}$ 7.4. A decrease from $\mathrm{pH} 7.4$ to $\mathrm{pH} 3.5$ saw an almost four-fold increase in the charge under the voltammetric response (Figure $1 \mathrm{~B}$ inset). Hence, an acidic $\mathrm{pH}$ of 3.5 was chosen as an experimental condition for subsequent measurements in order to work with more defined voltammetric signature of haemoglobin.

A step forward from the investigation of electrochemistry of cellfree haemoglobin would be the measurement of such directly from intact red blood cells (RBCs) and blood. Such a measurement could provide better insights on actual electrochemical activity of iron ions in red blood cells in vivo. However, to eliminate the complications of biological environments, we began by studying these systems from a chemical point of view by obtaining the lyophilized forms of red blood cells and blood, and re-suspending them in phosphate buffers accordingly.

We investigated a solid state approach by sandwiching the red blood cell or blood layer between layers of Nafion that were deposited on the surface of a GC electrode to give GC-Nf-RBC-3Nf and GCNf-B-3Nf electrode surfaces respectively, as illustrated in Figure 2. Nafion contains a highly acidic sulfonate group, and is employed as a cation-exchange polymer. Electrodes coated with Nafion (and other surface confined molecules) have commonly been used to trap or concentrate solution phase species and thus improve their analytical detection ${ }^{19-21}$. In this work, the Nafion layers are thought to have two functions; (1) stabilizing matrix for RBCs on the GC electrode, and (2) to provide a readily exchangeable source of $\mathrm{H}^{+}$to molecules within the membranes to balance the charge as a result of electrochemical reductions.

To determine if it is possible to probe iron redox activity of haemoglobin directly from RBCs (lyophilized) and blood (lyophilized), cyclic voltammetry was used to study the reduction of red blood cells and blood on GC-Nf-RBC-3Nf and GC-Nf-B-3Nf electrodes, respectively. Figure $3 \mathrm{~A}$ compares the reduction of red blood cells to that of haemoglobin using the solid state approach. The reduction of haemoglobin started at $-0.05 \mathrm{~V}$ and showed a peak at $-0.30 \mathrm{~V}$. The same is observed for the reduction of red blood cells at concentrations $0.145 \mathrm{mg} / \mathrm{mL}$ RBCs and below. However, higher concentrations of red blood cells see a reduction starting at $-0.05 \mathrm{~V}$ and showing a peak at $-0.15 \mathrm{~V}$. The reduction peak potential is shifted to less negative values. It is interesting to note that the reduction peak potential for higher concentrations of red blood cells correspond to that of reduction of haemoglobin in solution $(-0.15 \mathrm{~V})$. Similarly, Figure $3 \mathrm{~B}$ compares the reduction of blood to that of haemoglobin. A reduction peak potential of $-0.30 \mathrm{~V}$ was observed for blood concentrations of $1 \times 10^{3}$ cells $/ \mu \mathrm{L}$ and below. At higher concentrations of blood, shifts of reduction peak potentials to less negative values were observed. Hence, it may be concluded that reduction peaks corresponding to haemoglobin were obtained directly from the (lyophilized) red blood cells and blood, despite the possible complications due to the presence of the cellular membrane and complex biological environments. Calibration to quantify the signal mag-

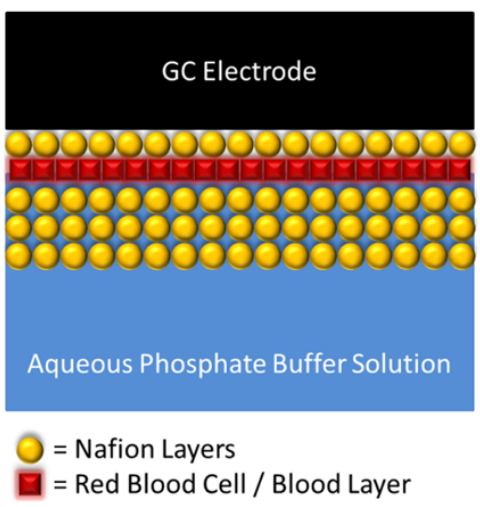

Figure $2 \mid$ Schematic diagram of the proposed structures of GC-Nf-RBC$3 \mathrm{Nf}$ and GC-Nf-B-3Nf electrode surfaces. 

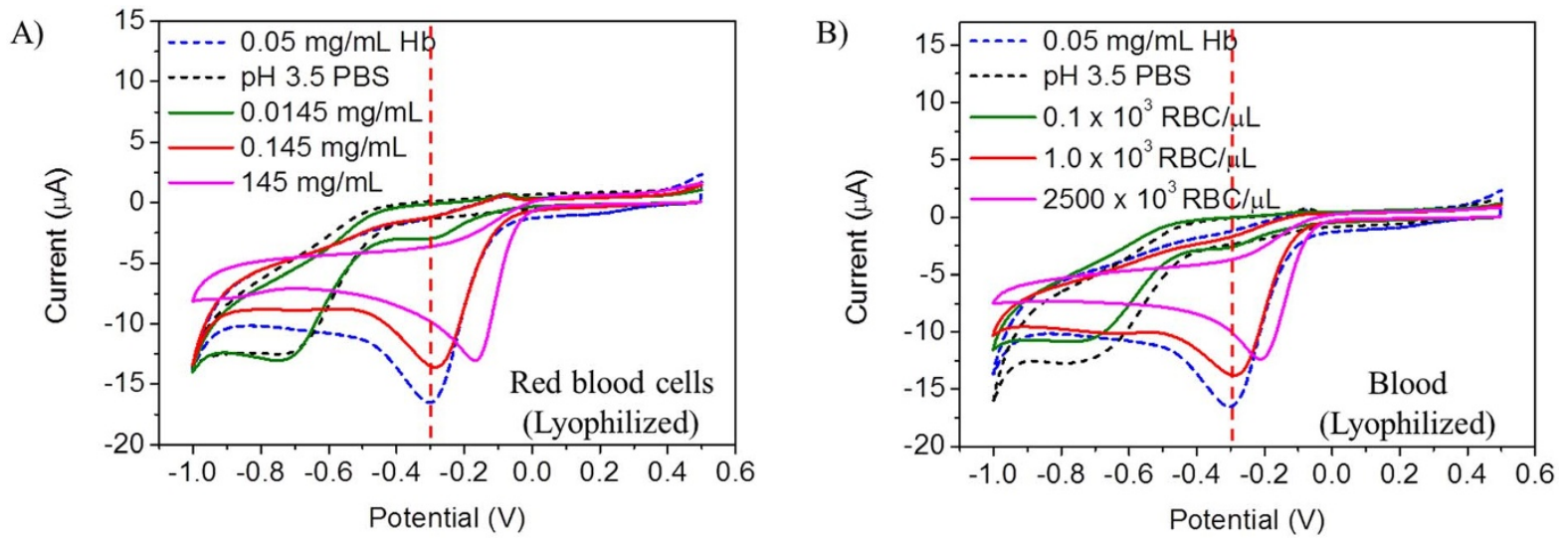

Figure $3 \mid$ (A) Cyclic voltammograms (from $+0.5 \mathrm{~V}$ to $-1.0 \mathrm{~V}$ ) were obtained in aqueous $50 \mathrm{mM}$ phosphate buffer at $\mathrm{pH} 3.5$ for the electrochemical reduction of red blood cells (powder) at GC-Nf-RBC-3Nf electrodes. Scan rate is $0.1 \mathrm{Vs}^{-1}$. Control experiments were performed using $\mathrm{Hb}$ (blue dotted line) and pH 3.5 PBS (black dotted line). (B) Cyclic voltammograms (from $+0.5 \mathrm{~V}$ to $-1.0 \mathrm{~V}$ ) were obtained in aqueous $50 \mathrm{mM}$ phosphate buffer at $\mathrm{pH} 3.5$ for the electrochemical reduction of blood at GC-Nf-B-3Nf electrodes. Legend shows concentrations of blood $\left(\mathrm{Cells}\left(\mathrm{x} 10^{3}\right) / \mu \mathrm{L}\right)$. Scan rate is $0.1 \mathrm{Vs}^{-1}$. Control experiments were performed using $\mathrm{Hb}$ (blue dotted line) and $\mathrm{pH}$ 3.5 PBS (black dotted line).

nitude against different concentrations of RBCs was conducted in a previous study of ours ${ }^{22}$.

Having established that the reduction signals from red blood cells (lyophilized) and blood (lyophilized) correspond to that of reduction of haemoglobin, it is equally important to determine the source of these signals: 1) directly from red blood cells or 2) free haemoglobin released into the supernatant due to lysis of the red blood cells. For this purpose, a lysis assessment was conducted. Scanning electron microscopy (SEM) images of red blood cells in powder form are shown in Figure 4 . The red blood cells exhibited mostly biconcave structures with diameters of about $3 \mu \mathrm{m}$. Crystals are observed on the membranes of the red blood cells. These crystals may be derived from the preparation process.

Cyclic voltammetry was used to investigate the reduction of red blood cells (lyophilized) before and after filtration (Figure 5). The filtration process would aid in removing any free haemoglobin released into the supernatant due to lysis of the red blood cells. It may be observed that the peak current magnitude dropped about four-fold from about $13 \mu \mathrm{A}$ before filtration to approximately $3 \mu \mathrm{A}$ from the filtrate or supernatant of the red blood cell suspension. The residue red blood cells obtained after filtration were re-suspended in pH 3.5 phosphate buffer. The peak current magnitude observed was similar to that of the red blood cell suspension before filtration.
Hence, the reduction signals observed may be derived directly from the red blood cells. To further support such a claim, optical microscopy of the red blood cells was performed before (Figures 6A-C) and after (Figure 6D-F) filtration. The images obtained were similar before and after filtration, showing no substantial lysis of the red blood cells.

Moreover, it is crucial to understand the concentration dependence of the voltammetric signals. Cyclic voltammetry (CV) was used to study the reduction of red blood cells (Figure 7A) and blood (Figure 7B) on GC-Nf-RBC-3Nf and GC-Nf-B-3Nf electrodes respectively and the insets illustrates the calibration plot obtained correspondingly. Calibration of the signal response against red blood cell concentration may act as a crucial clinical diagnosis of the oxygen transport ability of a blood sample. From Figure 7A, the red blood cell concentration range over which peak current is proportional to concentration ranges from 0 to $1.45 \mathrm{mg} / \mathrm{mL}$. Saturation of concentration dependence is observed with red blood cell concentrations higher than $1.45 \mathrm{mg} / \mathrm{mL}\left(50 \times 10^{3}\right.$ cells $\left./ \mu \mathrm{L}\right)$. Figure $7 \mathrm{~B}$ shows that the blood concentration range over which the peak current is proportional to concentration may be estimated to be from 0 to $5 \times$ $10^{3}$ cells $/ \mu \mathrm{L}$. At blood concentrations higher than $5 \times 10^{3}$ cells $/ \mu \mathrm{L}$, peak current magnitude decreases with an increase in blood concentration. Red blood cells in blood samples were quantified by taking
A)

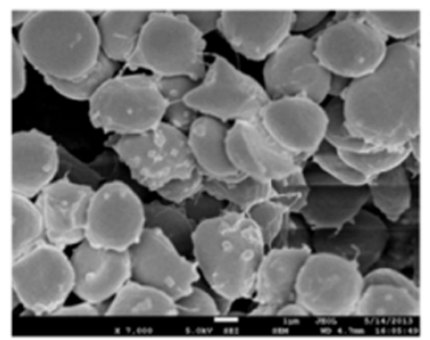

D)

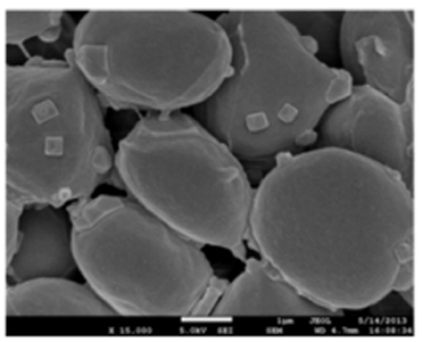

B)

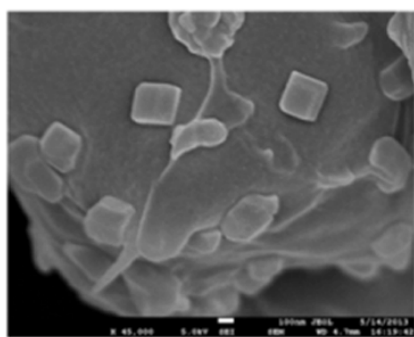

E)

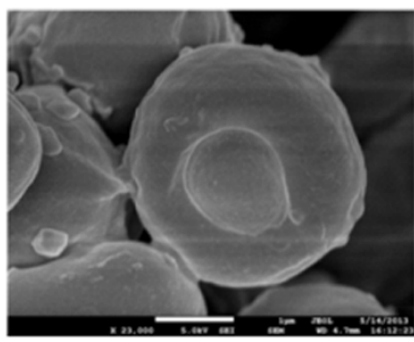

C)
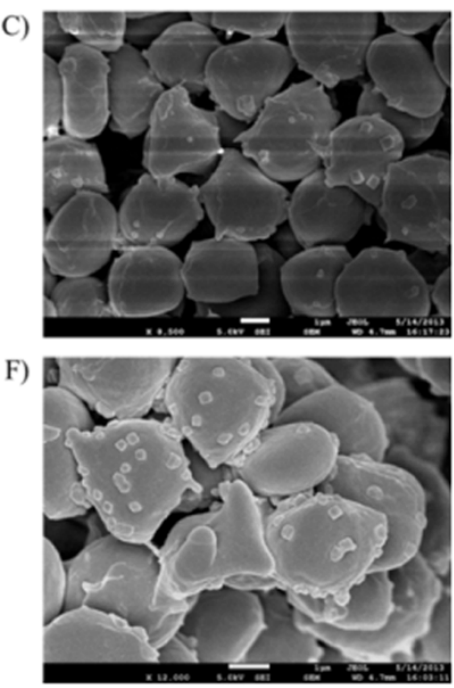

Figure 4 | Scanning electron microscopy (SEM) of red blood cells (lyophilized) at $5.0 \mathrm{kV}$. Red blood cells have diameters of about $3 \mu \mathrm{m}$. 


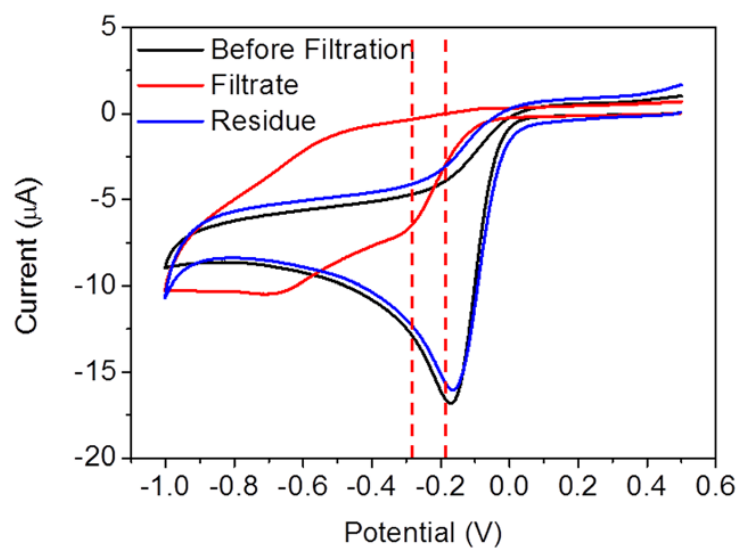

Figure $5 \mid$ Cyclic voltammograms (from $+0.5 \mathrm{~V}$ to $-1.0 \mathrm{~V}$ ) were obtained in aqueous $50 \mathrm{mM}$ phosphate buffer at $\mathrm{pH} 3.5$ for the electrochemical reduction of red blood cells before filtration (black line) and after filtration; filtrate (red line) and re-suspended residue (blue line) at GC-Nf-RBC-3Nf electrodes. Red blood cell concentration $=72.5 \mathrm{mg} /$ $\mathrm{mL}\left(2500 \times 10^{3}\right.$ cells $\left./ \mu \mathrm{L}\right)$. Scan rate is $0.1 \mathrm{Vs}^{-1}$.

reference to a standard average $\mathrm{RBC}$ count of $5000 \times 10^{3}$ cells per microliter of blood in a healthy individual ${ }^{23}$. The linear response ranges obtained in both cases are very narrow. This would imply the need for high dilutions during sample preparation. However, such an observation would mean that the volume of blood sample required may be minimized. This is a critical advantage in clinical studies where volume and frequency of blood withdrawal are of concern.

Our experiments hitherto investigated the chemical systems of red blood cells and blood. However, these systems do not completely replicate that of real biological systems as they do not have regulation and feedback mechanisms. In biological systems, most parameters are required to stay within a narrow range around a certain optimal level under certain environmental conditions. The maintenance of this optimal level for a parameter is known as homeostasis. One of the challenges faced would be the uncertainty in behaviour of voltammetric responses from real blood samples due to homeostatic processes.

In order to study the voltammetric responses from real biological systems, we employed human red blood cells (live) derived directly from real blood samples. Similar to experiments carried out previously, a solid state approach was taken by sandwiching the red blood cell layer between layers of Nafion that were deposited on the surface of a GC electrode (GC-Nf-RBC-3Nf) as illustrated in Figure 2. Cyclic voltammetry $(\mathrm{CV})$ was used to study the reduction of red blood cells (live) obtained directly from real blood samples on GC-Nf-RBC-3Nf electrodes (Figure 8). Comparison was made between the voltammetric responses derived from the electrochemical reduction of red blood cells (live) and red blood cells (lyophilized). The reduction of red blood cells in both cases starts at $+0.05 \mathrm{~V}$ and shows a peak at $-0.15 \mathrm{~V}$. Therefore, the similar reduction potentials and shape of cyclic voltammograms observed points to the possibility of probing haemoglobin activity from a real biological system without much interference.

The reproducibility of the proposed biosensor for haemoglobin in red blood cells (live) was investigated at $50 \mathrm{mM}$ phosphate buffer solution. The relative standard deviation was $4.3 \%(n=3)$ for three successive measurements demonstrated that the electrode-to-electrode reproducibility is acceptable in the response of three biosensors prepared under the same conditions independently. Hence, it may be established that the analyte is stable during electrode modification and electrochemical measurements.

In conclusion, a simple protocol was developed for the immobilization of RBCs or blood on a glassy carbon electrode using Nafion. On the modified electrode, direct detection of haemoglobin from RBCs and blood samples were realized at pH 3.5 PBS, which may allow for quantitative analysis of red blood cells in blood samples for clinical diagnosis. Stability of the analyte under the proposed experimental conditions was demonstrated by the high reproducibility of the experiments. Moreover, it is important to consider what is happening at the iron centre of haemoglobin during measurements. For this purpose, we consider the experimental conditions employed. The above experiments were performed under aerobic conditions.
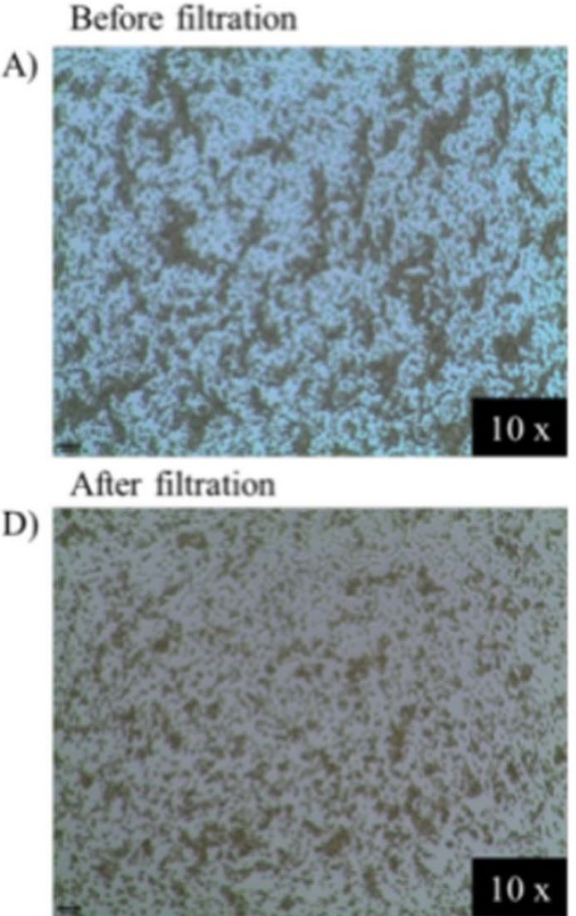

B)

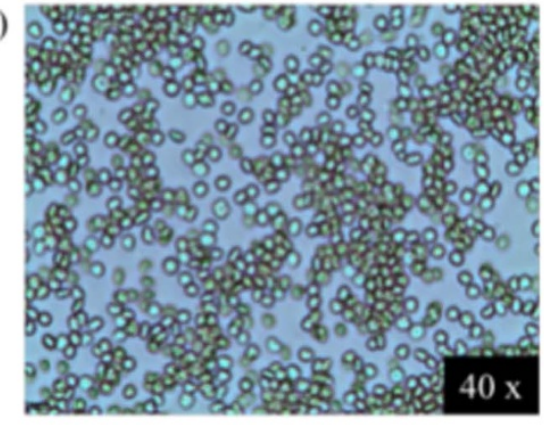

E)

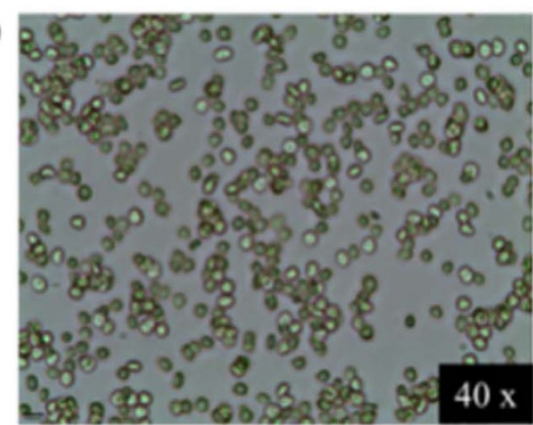

C)

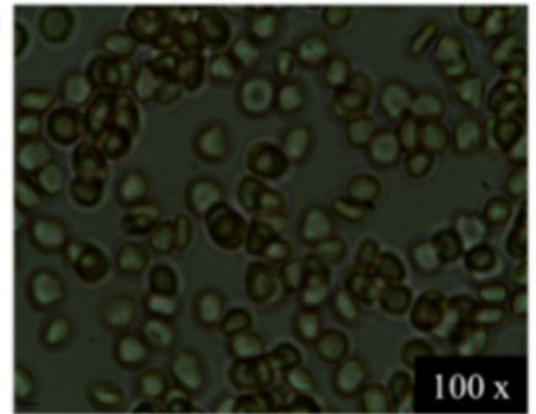

F)

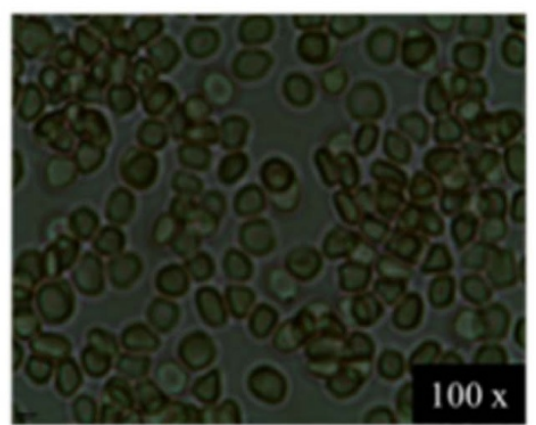

Figure 6 Optical microscopy of red blood cells before (A-C) and after (D-F) filtration. 

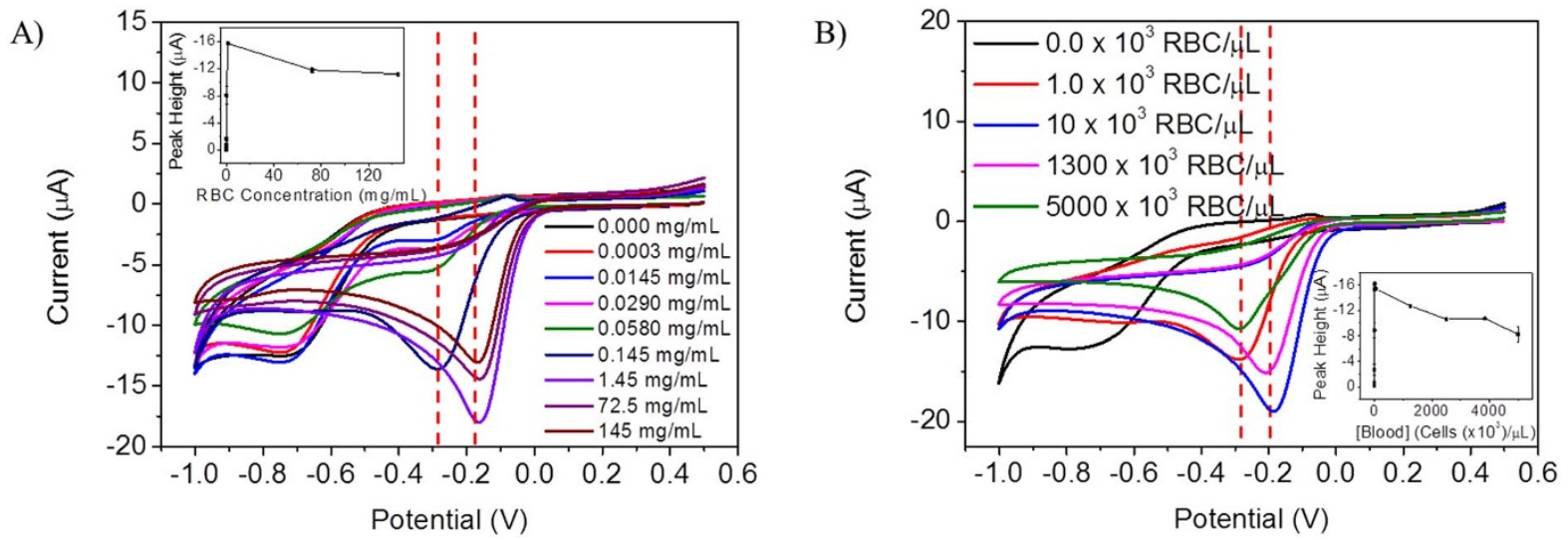

Figure $7 \mid$ (A) Cyclic voltammograms (from $+0.5 \mathrm{~V}$ to $-1.0 \mathrm{~V}$ ) were obtained in aqueous $50 \mathrm{mM}$ phosphate buffer at $\mathrm{pH} 3.5$ for the electrochemical reduction of red blood cells at GC-Nf-RBC-3Nf electrodes. Legend shows concentrations of RBC (mg/mL). Scan rate is $0.1 \mathrm{Vs}^{-1}$. Inset: Reduction peak height corresponding to different concentrations of RBC. The calibration curve observed concentration saturation starting at $1.45 \mathrm{mg} / \mathrm{mL}(50 \times$ $10^{3}$ cells $/ \mu \mathrm{L}$ ). Error bars represent RSD $(n=3 ; 95 \%$ confidence interval). (B) Cyclic voltammograms (from $+0.5 \mathrm{~V}$ to $-1.0 \mathrm{~V}$ ) were obtained in aqueous $50 \mathrm{mM}$ phosphate buffer at $\mathrm{pH} 3.5$ for the electrochemical reduction of blood at GC-Nf-B-3Nf electrodes. Legend shows concentrations of blood (Cells $\left.\left(\mathrm{x} 10^{3}\right) / \mu \mathrm{L}\right)$. Scan rate is $0.1 \mathrm{Vs}^{-1}$. Inset: Reduction peak height corresponding to different concentrations of blood. The calibration curve observed concentration saturation starting at $5 \times 10^{3}$ cells $/ \mu \mathrm{L}$. Error bars represent RSD ( $n=3 ; 95 \%$ confidence interval).

$\mathrm{HbFe}^{\mathrm{II}}$ reacts rapidly with oxygen to give $\mathrm{HbFe}^{\mathrm{II}}-\mathrm{O}_{2}{ }^{24}$. With comparison to previous research, it is most probable that the reduction peak from haemoglobin in the range of $-0.15 \mathrm{~V}$ to $-0.3 \mathrm{~V}$ corresponds to the electrochemical reduction of the $\mathrm{HbFe}^{\mathrm{II}}-\mathrm{O}_{2}$ complex to give $\mathrm{HbFe}^{\mathrm{II}}$ and hydrogen peroxide ${ }^{25,26}$. Obviously, there leaves much to be studied about the mechanism involved. We believe that such a biosensor shows great promise for the study of the physiological status of RBCs in real blood samples for scientific and clinical purposes.

\section{Methods}

Materials. $N, N$-dimethylformamide (DMF) was purchased from Merck. Potassium phosphate dibasic $\left(\mathrm{K}_{2} \mathrm{HPO}_{4}\right)$, phosphoric acid $\left(\mathrm{H}_{3} \mathrm{PO}_{4}, \geq 85 \mathrm{wt}\right.$. \% in $\left.\mathrm{H}_{2} \mathrm{O}\right)$, Nafion 117 solution $(\sim 5 \mathrm{wt} \%$ in a mixture of lower aliphatic alcohols and water), haemoglobin human (lyophilized powder), red blood cells from sheep (dry powder, glutaraldehyde treated) were obtained from Sigma-Aldrich. Lyophilized human

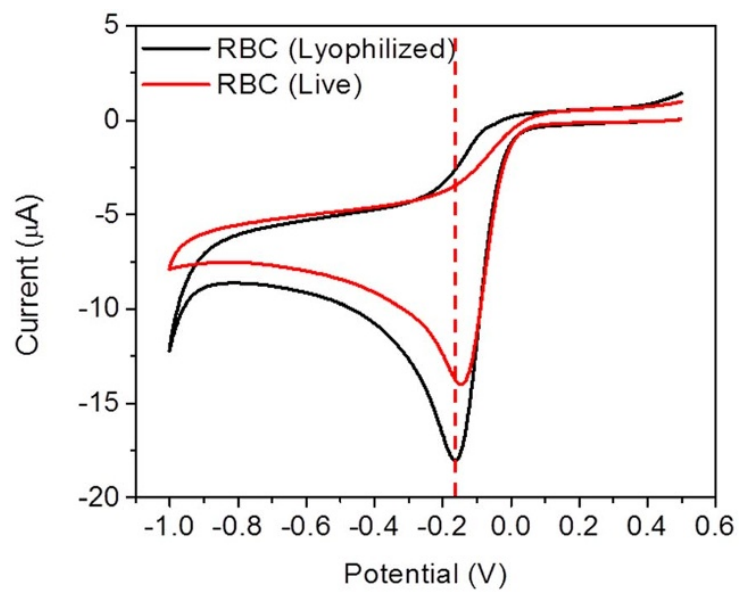

Figure $8 \mid$ Cyclic voltammograms (from $+0.5 \mathrm{~V}$ to $-1.0 \mathrm{~V}$ ) were obtained in aqueous $50 \mathrm{mM}$ phosphate buffer at $\mathrm{pH} 3.5$ for the electrochemical reduction of red blood cells (live) at GC-Nf-RBC-3Nf electrodes. Comparison was made between red blood cells purchased from Sigma Aldrich in powder form (black line, RBCs suspended in pH 3.5 PBS, RBC concentration of $1.45 \mathrm{mg} / \mathrm{mL}, 50 \times 10^{3}$ cells $/ \mu \mathrm{L}$ ) and red blood cells derived directly from blood samples (red line, $\mathrm{RBCs}$ suspended in $\mathrm{pH} 7.4$ $1 \times$ PBS, RBC concentration of approximately $10 \%$ vol.). Scan rate is $0.1 \mathrm{~V} \mathrm{~s}^{-1}$. whole blood was obtained from the Institute for Reference Materials and Measurements and reconstituted as described in the instructions for use. Human red blood cells (live) were obtained from i-DNA Biotechnology Pte Ltd. Glassy-carbon (GC), $\mathrm{Ag} / \mathrm{AgCl}$ reference, and Pt counter electrodes were obtained from Autolab (Japan).

Apparatus. All voltammetric experiments were carried out by using a $\mu$ Autolab type III electrochemical analyser (Eco Chemie, The Netherlands) connected to a computer and controlled by General Purpose Electrochemical Systems, Version 4.9 software (GPES). Electrochemical experiments were conducted in an electrochemical cell $(5 \mathrm{~mL})$ at room temperature. A three-electrode configuration was employed. A platinum electrode served as the auxiliary electrode, and an $\mathrm{Ag} / \mathrm{AgCl}$ electrode functioned as the reference electrode. All electrochemical potentials in this paper are stated versus $\mathrm{Ag} / \mathrm{AgCl}$ reference electrode.

Preparation of Electrode Surfaces. Glassy carbon (GC) working electrode surfaces were renewed by polishing with $0.05 \mu \mathrm{m}$ alumina particles on a polishing pad. A $1 \mu \mathrm{L}$ droplet of Nafion solution was placed on the electrode surface with a micropipette. The solvent was then allowed to dry in air for $5 \mathrm{~min}$. Subsequently, a $1 \mu \mathrm{L}$ aliquot of the analyte solution was deposited on top of the Nafion layer. $3 \mu \mathrm{L}$ droplets of the Nafion solution were then deposited on top of the analyte layer in three separate $1 \mu \mathrm{L}$ deposition steps. The solvent was allowed to evaporate for $5 \mathrm{~min}$ after each addition. The optimal coating procedure described above was determined by a number of trial and error experiments, and further supported by a previous research ${ }^{27}$. The resulting modified electrode was abbreviated as GC-Nf-RBC-3Nf or GC-Nf-B-3Nf with red blood cells or blood as the analyte respectively.

Electrochemical measurements. Cyclic voltammetry experiments were performed at a scan rate of $100 \mathrm{mV} \mathrm{s}^{-1}$ in phosphate buffer solution (pH 3.5, $\left.50 \mathrm{mM}\right)$ as supporting electrolyte.

1. Lei, C., Wollenberger, U., Bistolas, N., Guiseppi-Elis, A. \& Scheller, F. W. Electron transfer of hemoglobin based on colloidal clay nanoparticles. Anal. Bioanal. Chem. 372, 235-239 (2002)

2. Weissbluth, M. Hemoglobin, Cooperativity And Electronic Properties: Molecular Biology Biochemistry And Biophysics (Springer, Berlin, , Heidelberg, New York, 1974).

3. Guerriero, S. E. Methemoglobinemia caused by topical benzocaine. Pharmacotherapy 17, 1038-1040 (1997).

4. Rehman, H. U. Methemoglobinemia. West J. Med. 175, 193-196 (2001).

5. Boylston, M. \& Beer, D. Methemoglobinemia: a case study. Crit. Care Nurse 22, 50-55 (2002)

6. Paleček, E. et al. Sensitive electrochemical determination of unlabeled MutS protein and detection of point mutations in DNA. Anal. Chem. 76, 5930-5936 (2004).

7. Masarik, M. et al. Sensitive electrochemical detection of native and aggregated $\alpha$ synuclein protein involved in Parkinson's disease. Electroanal. 16, 1172-1181 (2004).

8. Krizkova, S., Adam, V., Eckschlager, T. \& Kizek, R. Using of chicken antibodies for metallothionein detection in human blood serum and cadmium-treated tumour cell lines after dot- and electroblotting. Electrophoresis 30, 3726-3735 (2009). 
9. Masarik, M. et al. Application of avidin-biotin technology and adsorptive transfer stripping square-wave voltammetry for detection of DNA hybridization and avidin in transgenic avidin maize. Anal. Chem. 75, 2663-2669 (2003).

10. Lasey, R. C., Liu, L., Zang, L. \& Ogawa, M. Y. Peptide-protein interactions: photoinduced electron-transfer within the preformed and encounter complexes of a designed metallopeptide and cytochrome c. Biochemistry $\mathbf{4 2}$, 3904-3910 (2003).

11. Jeuken, L. J. C., Jones, A. K., Chapman, S. K., Cecchini, G. \& Armstrong, F. A. Electron-transfer mechanisms through biological redox chains in multicenter enzymes. J. Am. Chem. Soc. 124, 5702-5713 (2002).

12. Bunn, H. F. \& Aster, J. C. Pathophysiology of Blood Disorders (McGraw-Hill Medical, New York, 2011).

13. Moore, G., Knight, G. \& Blann, A. Haematology (Oxford, Oxford UP, New York, 2010).

14. Gu, H. Y. et al. A novel nitric oxide cellular biosensor based on red blood cells immobilized on gold nanoparticles. Anal. Lett. 39, 2849-2859 (2006).

15. Wu, Y. H., Shen, Q. C. \& Hu, S. S. Direct electrochemistry and electrocatalysis of heme-proteins in regenerated silk fibroin film. Anal. Chim. Acta 558, 179-186 (2006)

16. Han, X. J., Huang, W. M., Jia, J. B., Dong, S. J. \& Wang, E. K. Direct electrochemistry of hemoglobin in egg-phosphatidylcholine films and its catalysis to $\mathrm{H}_{2} \mathrm{O}_{2}$. Biosens. Bioelectron. 17, 741-746 (2002).

17. Paddon, C. A. \& Marken, F. Hemoglobin adsorption into $\mathrm{TiO}_{2}$ phytate multi-layer films: particle size and conductivity effects. Electrochem. Commun. 6, 1249-1253 (2004)

18. Chen, X., Fu, C. \& Yang, W. Graphite nanosheet-based composites for mediatorfree $\mathrm{H}_{2} \mathrm{O}_{2}$ biosensor. Analyst 134, 2135-2140 (2009).

19. Kawagoe, K. T., Garris, P. A., Wiedemann, D. J. \& Wrightman, R. M. Regulation of transient dopamine concentration gradients in the microenvironment surrounding nerve terminals in the rat striatum. Neuroscience 51, 55-64 (1992).

20. Ugo, P. \& Moretto, L. M. Ion-exchange voltammetry at polymer-coated electrodes: principles and analytical prospects. Electroanal. 7, 1105-1113 (1995).

21. George, S. \& Lee, H. K. Direct electrochemistry and electrocatalysis of hemoglobin in nafion/carbon nanochip film on glassy carbon electrode. J. Phys. Chem. B 113 , 15445-15454 (2009).

22. Toh, R. J., Peng, W. K., Han, J. \& Pumera, M. Haemoglobin electrochemical detection on various reduced graphene surfaces: well-defined glassy carbon electrode outperforms the graphenoids. RSC Adv. 4, 8050-8054 (2014).

23. Beutler, E., Lichtman, M. A., Coller, B. S. \& Kipps, T. J. Williams Hematology [Sixth ed.] (McGraw-Hill, Inc., New York, 2001).
24. Antonini, E. \& Brunori, M. Hemoglobin and Myoglobin in their Reactions with Ligands (North Holland, Amsterdam, 1971).

25. Onuoha, A. C., Zu, X. \& Rusling, J. F. Electrochemical Generation and Reactions of Ferrylmyoglobins in Water and Microemulsions. J. Am. Chem. Soc. 119, 3979-3986 (1997).

26. Yu, C., Wang, L., Zhu, Z., Bao, N. \& Gu, H. Trans-membrane electron transfer in red blood cells immobilized in a chitosan film on a glassy carbon electrode. Microchim. Acta 181, 55-61 (2014).

27. Yao, W. W., Lau, C., Hui, Y., Poh, H. L. \& Webster, R. D. Electrode-supported biomembrane for examining electron-transfer and ion-transfer reactions of encapsulated low molecular weight biological molecules. J. Phys. Chem. C 115, 2100-2113 (2011).

\section{Acknowledgments}

M.P. thanks NAP (NTU) fund. R.J.T., W.K.P., J.H. and M.P. acknowledge financial support from SMA3 Singapore - MIT Alliance for Research and Technology (SMART) Centre, BioSystems and Micromechanics (BioSyM) IRG, Singapore.

\section{Author contributions}

M.P. and J.H. devised experiments, R.J.T. performed measurements, R.J.T. and M.P. analyzed data. M.P., R.J.T., J.H. and W.K.P. discussed the data and contributed writing the manuscript.

\section{Additional information}

Competing financial interests: The authors declare no competing financial interests.

How to cite this article: Toh, R.J., Peng, W.K., Han, J. \& Pumera, M. Direct In Vivo Electrochemical Detection of Haemoglobin in Red Blood Cells. Sci. Rep. 4, 6209; DOI:10.1038/srep06209 (2014).

This work is licensed under a Creative Commons Attribution-NonCommercialNoDerivs 4.0 International License. The images or other third party material in this article are included in the article's Creative Commons license, unless indicated otherwise in the credit line; if the material is not included under the Creative Commons license, users will need to obtain permission from the license holder in order to reproduce the material. To view a copy of this license, visit http:// creativecommons.org/licenses/by-nc-nd/4.0/ 